\title{
Do Consumers Learn from Their Own Experiences?
}

April 12, 2012

\author{
Kiichi Tokuoka \\ International Monetary Fund \\ ktokuoka@gate01.com \\ ktokuoka@imf.org
}

\begin{abstract}
It is natural to think that a household may learn from its own negative experiences and subsequently increase savings. The implications of such informal learning for the aggregate economy may be quite important, for example, after a sharp increase in unemployment following an economic crisis. This paper tests the hypothesis that Japanese households learn from their experiences of large expenditure and increase their targets for precautionary savings after such experiences. The results imply that households raise their targets for precautionary savings by 5-7 percent of annual income in response to such experiences. Moreover, data are consistent with the argument that targets for savings affect actual savings. Assuming this holds, the results in this paper suggest that consumers may increase their actual savings following a negative financial experience.
\end{abstract}

Keywords Learning, Precautionary savings, Target

JEL codes D12, D83

I am grateful to Damiano Sandri and Masato Nakane for their insightful comments to an earlier version of the paper The views expressed in this paper are my own and do not necessarily represent those of the International Monetary Fund. 


\section{Introduction}

Despite growing literature on learning in the field of macroeconomic policy, ${ }^{1}$ economists have not paid much attention to the effect of learning on decision making between consumption and saving. ${ }^{2}$ While Several recent works have started to examine the effectiveness of formal learning in such decision making (e.g., attending retirement seminars), ${ }^{3}$ work on informal learning remains particularly limited, with a few exceptions (e.g., Lusardi (2003); Allen and Carroll (2001)). Economists have a good reason for assuming away learning in a saving model: if we seriously take learning into account (in particular, in a heterogeneous agents model), we need to know the distribution of information to obtain aggregate implications, which may substantially complicate the model.

It is, however, natural to think that a household may learn from its own negative experiences and subsequently increase savings. The implications of such informal learning for the aggregate economy may be quite important, for example, after a sharp increase in unemployment following an economic crisis. One could test for this type of learning by regressing (the change in) the wealth to permanent income ratio on the dummy of an own negative experience (e.g., large expenditure, income shock). However, this test is subject to a serious identification problem because those who have experienced a negative experience typically reduce savings. ${ }^{4}$

This paper steps back and considers an alternative hypothesis: a household's negative experience may affect its target for precautionary savings. I test this hypothesis using the Japanese Panel Survey of Consumers (JPSC), which records targets for precautionary savings. Of course, testing this hypothesis is not the same as testing whether own negative experience affects savings behavior (updating the target for savings does not necessarily mean a change in behavior), but this is a step forward in understanding household saving and consumption decision making.

The results in this paper support the hypothesis that households' perceptions change after experiencing an adverse financial experience, with estimated coefficients suggesting that in Japan households raise their targets for precautionary savings by $5-7$ percent of (permanent) income after large expenditure. Moreover, the data are consistent with the argument that the targets for savings affect actual savings. Assuming this holds, the results imply that households save more (than others) following large expenditure.

This paper is closely related to that of Owen and Wu (2007). Using the Health and Retirement Study (HRS) and the Survey of Consumer Finances (SCF), ${ }^{5}$ they show that households experiencing negative financial shocks worry more about the adequacy of their retirement savings; however, the present paper focuses on precautionary savings.

\footnotetext{
${ }^{1}$ See, for example, Evans and Honkapohja (2009) for a comprehensive list of literature on monetary policy. Outside of the traditional areas of economics, Giuliano and Spilimbergo (2009) have shown that those who grew up during recessions tend to support government redistribution.

${ }^{2}$ Some studies have been done on the role of learning in households' investment decisions (e.g., Malmendier and Nagel (2011); Kaustia and Knupfer (2008); Ameriks and Zeldes (2004)).

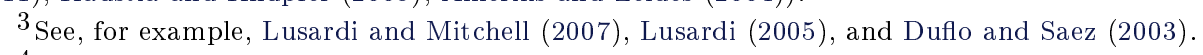

${ }^{4}$ In fact, I have found that large expenditure is estimated to reduce actual liquid assets by 5 percent of income (using this paper's data set).

${ }^{5}$ Both are the U.S. data.
} 
I complement Owen and Wu (2007)'s work by quantifying the impact of a negative financial shock, whereas they examine the qualitative impact of such a shock.

The next section presents the econometric model, and Section 3 describes the data. Section 4 reports the results, followed by conclusions.

\section{Econometric Model}

The econometric model used in this paper is based on the buffer stock model (Carroll (1997)). The buffer stock model implies that in period $t$, household $i$ has a target level $m_{i, t}^{*}$ for its (precautionary) savings to permanent noncapital income ratio:

$$
M_{i, t}^{*} / P_{i, t}=m_{i, t}^{*},
$$

where $M_{i, t}^{*}$ is the target for precautionary savings (level) and $P_{i, t}$ is permanent noncapital income. This implies:

$$
\begin{aligned}
\left(M_{i, t}^{*}-M_{i, t-1}^{*}\right) / P_{i, t} & =m_{i, t}^{*}\left(1-\frac{m_{i, t-1}^{*}}{m_{i, t}^{*}} \frac{P_{i, t-1}}{P_{i, t}}\right) \\
\Delta M_{i, t}^{*} / P_{i, t} & =m_{i, t}^{*}\left(1-\left(1 / \Gamma_{i, t}\right)\left(1 / G_{i, t}\right)\right),
\end{aligned}
$$

where $\Gamma_{i, t} \equiv \frac{m_{i, t}^{*}}{m_{i, t}^{*}-1}$ and $G_{i, t} \equiv \frac{P_{i, t}}{P_{i, t}-1}$.

Assuming that $m_{i, t}^{*}\left(1-\left(1 / \Gamma_{i, t}\right)\left(1 / G_{i, t}\right)\right)$ in (1) is controlled for by demographic variables, we consider the following econometric model: ${ }^{6}$

$$
\Delta M_{i, t}^{*} / P_{i, t}=\beta_{0}+\beta_{1} D_{i, t}+\beta_{2} \log P_{i, t}+\beta_{3} Z_{i, t}+\varepsilon_{i, t} .
$$

- The key variable is $D_{i, t}$, which is the dummy for whether the household has experienced a negative financial shock in the past year. The coefficient on $D_{i, t}$ should be positive if a household learns from its experience and subsequently increases its target for precautionary savings.

There are at least two potential mechanisms through which a household could increase its target for precautionary savings following an unfavorable financial event. First, its risk aversion could rise (simulations in Carroll (1997) confirm that the target wealth income ratio is higher with higher risk aversion). Second, it may revise its perceived probability of negative events upward. The second mechanism is consistent with the empirical findings of Guiso, Jappelli, and Terlizzese (1992), Lusardi (1997), and Lusardi (1998) that subjective earnings risks have a positive effect on wealth accumulation.

Using an own experience variable may involve the omitted variable problem. This is because own experience is likely to be highly correlated with unobservable individually specific factors such as ability and preferences. For example, those who are less able might be more likely to be hit by an accident that leads to a large

\footnotetext{
${ }^{6} \log P_{i, t}$ is included in the equation as there is empirical evidence that high-permanent-income households save more (Dynan, Skinner, and Zeldes (2004)).
} 
expenditure or an income loss. The problem is that such unobservable factors may not be fully captured by control variables, possibly creating a correlation between the error term and the key dummy ( $D_{i, t}$ in this paper). Using the fixed effects estimator $(\mathrm{FE})$ could alleviate this problem.

- $Z_{i, t}$ is a set of demographic variables and time dummies. Demographic variables consist of the age of the household head (husband) $;^{7}$ age squared; the number of family members; education dummies; industry dummies; and occupation dummies interacted with the dummy for whether or not the head has regular employment.

Since $P_{i, t}$ is not observable in reality, this paper estimates the equation by replacing $P_{i, t}$ in (2) with actual household total income $Y_{i, t}$. I estimate the model mainly using the instrumental variable (IV) method, using $\log Y_{i, t-1}$ as the instrument for $\log Y_{i, t}$ (throughout the IV regressions in this paper, I am using a one-year lag of $\log Y_{i, t}\left(\right.$ or $\left.Y_{i, t}\right)$ as the instrument). ${ }^{8}$ The panel structure of the data (discussed below) allows the use of the FE as well. Under the assumption that individually specific unobservable elements such as preferences are time-invariant,${ }^{9}$ the $\mathrm{FE}$ corrects the omitted variable problem.

\section{Data}

The data used in the econometric analysis are taken from the JPSC. The JPSC comprises Japanese annual panel data; it was started in 1993, with its latest available data point being 2007. The initial 1993 survey covered 1,500 women aged 24-33; in 1997, women aged 24-27 were added to the sample, and in 2003, those aged 24-29 were added. Although the JPSC tracks only women (either single or married) as respondents, married women's husbands' data are also available. It offers a rich set of variables, including those related to savings, income, age, education, and employment.

In particular, the JPSC asks two questions that are critical for this paper. The first is: "How much are your household's target savings for unexpected expenses such as illness, disaster, and so on?" I interpret this as the target for precautionary savings and use it as $M_{i, t}^{*}$ below. ${ }^{10}$ The second is: "Which of the following has your household experienced: i) large expenditure; and/or ii) income and/or wealth decline?"11 I use the answer to the second question to construct $D_{i, t}{ }^{12}$ Questions similar to these two questions are

\footnotetext{
${ }^{7}$ I assume that the husband is the head because in more than 90 percent of the households in the data set, the husband's income is higher than that of the wife.

${ }^{8}$ Equation (2) tells us that the dependent variable should be $M_{i, t}^{*} / P_{i, t}$, but $Y_{i, t}$, which includes a transitory component, is used as an estimate for $P_{i, t}$. This can be seen as a measurement error problem, and the error term $\varepsilon_{i, t}$ picks up the transitory component in $Y_{i, t}$. The correlation between the error term and log $Y_{i, t}$ (an estimate for $\left.\log P_{i, t}\right)$ requires instrumenting $\log Y_{i, t}$.

${ }^{9}$ Examples of such unobservable elements include preferences, but $Z_{i, t}$ is unlikely to fully control for them.

${ }^{10}$ The intention of this question is to obtain the target for precautionary savings. However, the possibility that misreporting occurs cannot be denied. For example, some households might include expected expenses for illness. If so, the responses also cover life-cycle savings because, in a pure sense, precautionary savings should cover only savings for unexpected events.

${ }^{11}$ The full list includes several other experiences (e.g., the wife's depression), but they are omitted here because they are not relevant to this paper's hypothesis.

${ }^{12}$ The JPSC introduced this question in 1994 (it is not in the initial 1993 survey).
} 
also asked in the $\mathrm{SCF},{ }^{13}$ which could allow researchers to conduct a similar test using the SCF. However, the advantage in the JPSC is that it is a panel data and thus we can test dynamics in saving behavior, while the SCF is not.

In my data set, I have included only married households; restricted the head's (husband)'s age to between 20 and 60 to avoid the impact of retirement; and measured financial variables in 1993 prices (using headline CPI). In addition, in each of the regressions below, the top and bottom 1 percent of the dependent variable are trimmed (as the distribution is very wide). Summary statistics of key variables (used for the IV regressions reported in Table 1) are reported in Appendix A.

\section{Results}

Do households raise targets for precautionary savings after adverse events? The results by estimating equation (2) provide support for the hypothesis that households increase their targets for savings following a negative financial event. When setting $D_{i, t}$ at 1 if household $i$ has experienced large expenditure over the past year, the coefficient estimated by IV is positive and significant (first column of Table 1). The results are robust with the choice of the instrument. ${ }^{14}$ The estimates using the FE (second column) are very similar to those of IV, providing no evidence against using IV despite the possible omitted variable problem (discussed above). The size of the coefficient on $D_{i, t}$ is about 5 percent, meaning that if a household experiences large expenditure, its target for precautionary savings rises by 5 percent of annual permanent (household) income. The third and fourth columns show that including the target for savings for comfort in $M_{i, t}^{*}$ gives similar coefficients on $D_{i, t}$ but these are no longer significant (possibly reflecting the smaller sample size ${ }^{15}$ ).

When setting the key dummy at 1 if the household has reduced income and/or wealth, the coefficient is insignificant although still positive (fifth and sixth columns). This could be because following a negative income shock, some households may learn that their future permanent income has declined and cut their targets for precautionary savings accordingly. From this point, this paper focuses on an experience of large expenditure.

Is the perception change (change in $M_{i, t}^{*}$ ) persistent? The results provide some support for this, although they are mixed. Take $\Delta_{T} M_{i, t}^{*} / P_{i, t}=\left(M_{i, t}^{*}-M_{i, t-T}^{*}\right) / P_{i, t}$ as the dependent variable and $D_{i, t-(T-1)}$ (this is 1 if the household experienced large expenditure between $T-1$ and $T$ years ago) as the main independent variable. If the effect of learning from high expenditure is persistent, the coefficient on $D_{i, t-(T-1)}$ should be positive because $M_{i, t}^{*}$ should remain high in response to the negative event between $T-1$ and $T$ years ago $\left(D_{i, t-(T-1)}=1\right)$. When $T=5$, the IV coefficient is significant

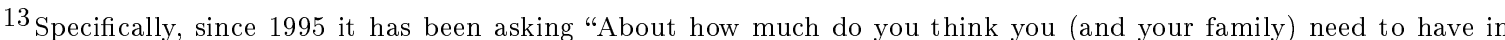
savings for emergencies and other unexpected things that may come up?". It also asks "Did you take out this mortgage to: refinance or rollover an earlier loan, borrow additional money on your home equity, or to do both?" and subsequently "For what purpose was the money used?" (these two questions could be used to identify events of expenditure).

${ }^{14}$ As noted above, the regression in the first column used a one-year lag of actual household income as the instrument. Using a two-year lag gives very similar results (not reported here).

15 More observations are missing for the target for savings for comfort than for precautionary savings.
} 
Table 1 Baseline Regressions

\begin{tabular}{|c|c|c|c|c|c|c|}
\hline VARIABLES & $\begin{array}{c}(1) \\
\text { IV } \\
\Delta M_{t}^{*} / P_{t}\end{array}$ & $\begin{array}{c}(2) \\
\mathrm{FE} \\
\Delta M_{t}^{*} / P_{t}\end{array}$ & $\begin{array}{c}(3) \\
\text { IV } \\
\Delta M_{t}^{*} / P_{t} \\
\text { inc. savings } \\
\text { for comfort }\end{array}$ & $\begin{array}{c}(4) \\
\mathrm{FE} \\
\Delta M_{t}^{*} / P_{t} \\
\text { inc. savings } \\
\text { for comfort }\end{array}$ & $\begin{array}{c}(5) \\
\text { IV } \\
\Delta M_{t}^{*} / P_{t}\end{array}$ & $\begin{array}{c}(6) \\
\mathrm{FE} \\
\Delta M_{t}^{*} / P_{t}\end{array}$ \\
\hline$D_{t}$ & $\begin{array}{c}0.052 \\
(0.014)^{* * *}\end{array}$ & $\begin{array}{c}0.047 \\
(0.014)^{* * *}\end{array}$ & $\begin{array}{c}0.052 \\
(0.038)\end{array}$ & $\begin{array}{c}0.063 \\
(0.049)\end{array}$ & & \\
\hline$\tilde{D}_{t}$ & & & & & $\begin{array}{c}0.029 \\
(0.022)\end{array}$ & $\begin{array}{c}0.023 \\
(0.026)\end{array}$ \\
\hline $\begin{array}{l}\text { Observations } \\
\text { R-squared } \\
\text { Number of id }\end{array}$ & $\begin{array}{l}7,787 \\
0.019\end{array}$ & $\begin{array}{l}8,394 \\
1,628\end{array}$ & $\begin{array}{l}5,699 \\
0.007\end{array}$ & $\begin{array}{l}6,150 \\
0.009 \\
1,477\end{array}$ & $\begin{array}{l}7,787 \\
0.017\end{array}$ & $\begin{array}{l}8,394 \\
0.019 \\
1,628\end{array}$ \\
\hline
\end{tabular}

Robust standard errors in parentheses

$* * * \mathrm{p}<0.01, * * \mathrm{p}<0.05,{ }^{*} \mathrm{p}<0.1$

(first column of Table 2), while the FE results are weak. When $T=7$, the results are weaker (third and fourth columns), suggesting that the perception change diminishes over time.

The results change little from the baseline (in Table 1) with an alternative estimate for permanent income. For example, the first two columns of Table 3 indicate that when using $P_{i, t}$ estimated using a three-year average $(t-1, t, t+1),{ }^{16}$ the results are almost identical to those reported in Table 1. A five-year average (columns three and four) yields very similar results.

The results are also robust using an alternative level specification: ${ }^{17}$

$$
\Delta M_{i, t}^{*}=\gamma_{0}+\gamma_{1} D_{i, t}+\gamma_{2} P_{i, t}+\gamma_{3} Z_{i, t}+\varepsilon_{i, t},
$$

where $Y_{i, t}$ (actual income) is used as an estimate of $P_{i, t}$. Using $Y_{i, t-1}$ as the instrument of $Y_{i, t}$, the coefficient on $D_{i, t}$ is about 40 thousand yen and highly significant (the last two columns of Table 3 ). This is about $6-7$ percent of average annual household incomeslightly higher than the magnitude estimated above (Table 1 and the first four columns of Table 3).

So far, this paper has not paid attention to events underlying large expenditure, but the JPSC allows us to examine their relevance. Before asking about the experience of such expenditure, the JPSC asks whether any of the family members (other than

\footnotetext{
${ }^{16}$ The idea of estimating $P_{i, t}$ using a multiyear average follows Carroll and Samwick (1998).

${ }^{17}$ This level specification may be misspecified. The level specification restricts the coefficient on $P_{i, t}$ to be constant across households, but equation (1) implies that if the coefficient on $P_{i, t}$ is proportional to $m_{i, t}^{*}$, it is heterogeneous across consumers.
} 
Table 2 Testing Persistence of Learning

\begin{tabular}{|c|c|c|c|c|}
\hline VARIABLES & $\begin{array}{c}(1) \\
\text { IV } \\
\Delta_{5} M_{t}^{*} / P_{t}\end{array}$ & $\begin{array}{c}(2) \\
\mathrm{FE} \\
\Delta_{5} M_{t}^{*} / P_{t}\end{array}$ & $\begin{array}{c}(3) \\
\text { IV } \\
\Delta_{7} M_{t}^{*} / P_{t}\end{array}$ & $\begin{array}{c}(4) \\
\mathrm{FE} \\
\Delta_{7} M_{t}^{*} / P_{t}\end{array}$ \\
\hline$D_{t-4}$ & $\begin{array}{c}0.068 \\
(0.027)^{* *}\end{array}$ & $\begin{array}{c}0.037 \\
(0.033)\end{array}$ & & \\
\hline$D_{t-6}$ & & & $\begin{array}{c}0.057 \\
(0.044)\end{array}$ & $\begin{array}{c}0.005 \\
(0.058)\end{array}$ \\
\hline Observations & 3,823 & 4,036 & 1,827 & 1,910 \\
\hline R-squared & 0.090 & 0.085 & 0.089 & 0.037 \\
\hline Number of id & & 1,067 & & 650 \\
\hline
\end{tabular}

Table 3 Robustness Checks

\begin{tabular}{lcccccc}
\hline & $(1)$ & $(2)$ & $(3)$ & $(4)$ & $(5)$ & $(6)$ \\
& $\mathrm{IV}$ & $\mathrm{FE}$ & $\mathrm{IV}$ & $\mathrm{FE}$ & $\mathrm{IV}$ & $\mathrm{FE}$ \\
& $\Delta M_{t}^{*} / P_{t}$ & $\Delta M_{t}^{*} / P_{t}$ & $\Delta M_{t}^{*} / P_{t}$ & $\Delta M_{t}^{*} / P_{t}$ & $\Delta M_{t}^{*}$ & $\Delta M_{t}^{*}$ \\
& $\mathrm{Alt}$ & $\mathrm{Alt}$ & $\mathrm{Alt}$ & $\mathrm{Alt}$ & $\mathrm{LV}$ & $\mathrm{LV}$ \\
& Perm & Perm & Perm & Perm & Spec & Spec \\
VARIABLES & $3 \mathrm{Yr} \mathrm{Av}$ & $3 \mathrm{Yr} \mathrm{Av}$ & $5 \mathrm{Yr} \mathrm{Av}$ & $5 \mathrm{Yr} \mathrm{Av}$ & & \\
\hline & & & & & & \\
$D_{t}$ & 0.055 & 0.057 & 0.057 & 0.053 & 41.8 & 44.1 \\
& $(0.017)^{* * *}$ & $(0.016)^{* * *}$ & $(0.019)^{* * *}$ & $(0.019)^{* * *}$ & $(13.4)^{* * *}$ & $(13.8)^{* * *}$ \\
Observations & 5,388 & 6,215 & 3,600 & 4,193 & 7,891 & 8,503 \\
R-squared & 0.026 & & 0.028 & & 0.017 & \\
Number of id & & 1,397 & & 1,103 & & 1,635 \\
\hline
\end{tabular}

Robust standard errors in parentheses *** $\mathrm{p}<0.01,{ }^{* *} \mathrm{p}<0.05,{ }^{*} \mathrm{p}<0.1$ 
Table 4 Regressions of Underlying Events

\begin{tabular}{|c|c|c|c|c|c|}
\hline VARIABLES & $\begin{array}{c}(1) \\
\text { OLS } \\
D_{t}\end{array}$ & $\begin{array}{c}(2) \\
\mathrm{IV} \\
\Delta M_{t}^{*} / P_{t}\end{array}$ & $\begin{array}{c}(3) \\
\text { IV } \\
\Delta M_{t}^{*} / P_{t}\end{array}$ & $\begin{array}{c}(4) \\
\mathrm{IV} \\
\Delta M_{t}^{*} / P_{t}\end{array}$ & $\begin{array}{c}(5) \\
\text { IV } \\
\Delta M_{t}^{*} / P_{t}\end{array}$ \\
\hline Dlongillness $_{t}$ & $\begin{array}{c}0.285 \\
(0.018)^{* * *}\end{array}$ & $\begin{array}{c}0.011 \\
(0.024)\end{array}$ & & & \\
\hline Daccdisaster $_{t}$ & $\begin{array}{c}0.256 \\
(0.022)^{* * *}\end{array}$ & & & $\begin{array}{l}-0.010 \\
(0.025)\end{array}$ & \\
\hline Dconsumertrouble $_{t}$ & $\begin{array}{c}0.310 \\
(0.040)^{* * *}\end{array}$ & & & & \\
\hline Dlongillness $_{t} \cdot D_{t}$ & & & $\begin{array}{c}0.049 \\
(0.040)\end{array}$ & & \\
\hline Daccdisaster $_{t} \cdot D_{t}$ & & & & & $\begin{array}{c}0.024 \\
(0.039)\end{array}$ \\
\hline Observations & 7,787 & 7,787 & 7,787 & 7,787 & 7,787 \\
\hline R-squared & 0.058 & 0.017 & 0.017 & 0.017 & 0.017 \\
\hline
\end{tabular}

the wife) has experienced adverse events, including: i) serious illness; ii) an accident or disaster; and iii) consumer trouble. The responses to this question can be used to examine the relevance of these events, which are highly correlated with the dummy of large expenditure (first column of Table 4).

Do any of these events have an impact on the target for precautionary savings? The results are weak. If the dummy of serious illness (of family members other than the wife) is used as the main variable, the coefficient is positive but insignificant (second column of Table 4). This may be because in many cases expenses from a (long) illness are not large enough to influence the targets for precautionary savings (no more than 60 percent of long illnesses are accompanied by large expenditure). However, even if the dummy of serious illness is interacted with the dummy of large expenditure, the coefficient remains insignificant (although becoming higher), which could be because the number of observations with the interaction term $=1$ is not large enough (at most 100). Using the dummy of an accident and/or a disaster gives similar results (last two columns of the table). (The results using the dummy of consumer trouble are weak (details omitted here) but they arise because of the small number of observations of consumer trouble (fewer than 60).)

Do targets for savings affect actual savings? Although the results above generally support the hypothesis that households that experience an expenditure shock increase 
their targets for savings, they do not explain whether households change their behavior after such a shock. We can shed some light on this question by examining the relation between actual savings and the target for savings. ${ }^{18}$

The data show that actual liquid assets $\left(M_{i, t}\right)$ and the target for precautionary savings $\left(M_{i, t}^{*}\right)$ are highly correlated (first four columns of Table 5). Of course, the regression results in the table are likely to be subject to the endogeneity problem as households with higher liquid assets may raise their targets for precautionary savings. Using a lagged variable as the main independent variable ${ }^{19}$ may correct the endogeneity problem (the last two columns of the table), but might still be subject to an omitted variable problem. For example, if a household knew in year $t-1$ that it would receive a positive income shock in year $t$, this would raise both $M_{i, t}$ and $M_{i, t-1}^{*}$, creating a positive coefficient on $M_{i, t-1}^{*}$ even when there is no causality from $M_{i, t-1}^{*}$ to $M_{i, t}$.

There is an alternative (and more theory-based) way to examine the relation between actual savings and the target for savings. The buffer stock model implies that the ratio of actual precautionary savings to permanent income converges to the target ratio in expectation (Carroll (2004)). By assuming that the rate of convergence in expectation $\left(\mathbb{E}\left[M_{i, t} / P_{i, t}-M_{i, t-1} / P_{i, t-1}\right]\right)$ is proportional to the deviation from the target ratio a year ago $\left(m_{i, t}^{*}-M_{i, t-1} / P_{i, t-1}=\left(M_{i, t-1}^{*}-M_{i, t-1}\right) / P_{i, t-1}\right)$, we can estimate:

$$
M_{i, t} / P_{i, t}-M_{i, t-1} / P_{i, t-1}=\alpha_{1}\left(M_{i, t-1}^{*}-M_{i, t-1}\right) / P_{i, t-1}+\epsilon_{i, t},
$$

where $\alpha_{1}>0$ is a parameter that determines the rate of convergence. Below, $M_{i, t}$ is liquid assets as a proxy for precautionary savings.

The results support the prediction of the buffer stock model. Estimating equation (4) (with the same control variables as before) gives a highly significant $\alpha_{1}$ (first column of Table 6). The estimate is about 0.08 , meaning that, on average, households close 8 percent of the deviation from the target in each year. Assessing whether or not this magnitude is reasonable is difficult, but it is within the (wide) range of estimates implied by the buffer stock model (see simulation results in Appendix B).

While equation (4) assumes that the rate of convergence is linearly proportional to the deviation from the target, it might be that the relation between convergence rate and deviation from the target is nonlinear. The second column of the table reports the results, allowing the nonlinearity by including the quadratic term of the deviation. Specifically, the following model is estimated:

$$
M_{i, t} / P_{i, t}-M_{i, t-1} / P_{i, t-1}=\alpha_{1}\left(M_{i, t-1}^{*}-M_{i, t-1}\right) / P_{i, t-1}+\alpha_{2}\left(\left(M_{i, t-1}^{*}-M_{i, t-1}\right) / P_{i, t-1}\right)^{2}+\epsilon_{i, t} .
$$

The results support nonlinearity (second column), but, with a reasonable deviation from the target, the impact of nonlinearity is quantitatively negligible because the estimated coefficient on the quadratic term is so small. This implies that the linearity assumption is broadly valid. Note also that the estimate of $\alpha_{1}$ changes very little from that reported in the first column. The estimation results of the level specification

\footnotetext{
18 As discussed in the introduction, investigating the correlation between actual savings and an expenditure shock does not work.

${ }^{19}$ An alternative approach is to use a lagged variable as the instrument.
} 
Table 5 Regressions of Convergence Process

\begin{tabular}{|c|c|c|c|c|c|c|}
\hline VARIABLES & $\begin{array}{c}(1) \\
\text { IV } \\
M_{t} / P_{t}\end{array}$ & $\begin{array}{c}(2) \\
\mathrm{IV} \\
\Delta M_{t} / P_{t} \\
\end{array}$ & $\begin{array}{l}(3) \\
\text { IV } \\
M_{t}\end{array}$ & $\begin{array}{c}(4) \\
\mathrm{IV} \\
\Delta M_{t} \\
\end{array}$ & $\begin{array}{c}(5) \\
\mathrm{IV} \\
M_{t} / P_{t} \\
\end{array}$ & $\begin{array}{l}(6) \\
\text { IV } \\
M_{t}\end{array}$ \\
\hline$M_{t}^{*} / P_{t}$ & $\begin{array}{c}0.269 \\
(0.038)^{* * *}\end{array}$ & & & & & \\
\hline$\Delta M_{t}^{*} / P_{t}$ & & $\begin{array}{c}0.031 \\
(0.010)^{* * *}\end{array}$ & & & & \\
\hline$M_{t}^{*}$ & & & $\begin{array}{c}0.297 \\
(0.040)^{* * *}\end{array}$ & & & \\
\hline$\Delta M_{t}^{*}$ & & & & $\begin{array}{c}0.033 \\
(0.015)^{* *}\end{array}$ & & \\
\hline$M_{t-1}^{*} / P_{t-1}$ & & & & & $\begin{array}{c}0.034 \\
(0.024)\end{array}$ & \\
\hline$M_{t-1}^{*}$ & & & & & & $\begin{array}{c}0.204 \\
(0.035)^{* * *}\end{array}$ \\
\hline Observations & 9,492 & 7,783 & 9,505 & 7,798 & 9,001 & 9,009 \\
\hline R-squared & 0.082 & 0.011 & 0.220 & 0.021 & 0.089 & 0.216 \\
\hline
\end{tabular}

Robust standard errors in parentheses

$* * * \mathrm{p}<0.01,{ }^{* *} \mathrm{p}<0.05,{ }^{*} \mathrm{p}<0.1$

Note: In the first two columns, the main independent variable was instrumented by its own numerator. This is because the denominator $\left(Y_{t}\right.$ as an estimate of $\left.P_{t}\right)$ in the main independent variable contains the same transitory component as the dependent variable does, which, without an appropriate instrument, might bias the coefficient on the main independent variable. 
Table 6 Regressions of Change in Actual Savings

\begin{tabular}{|c|c|c|c|c|}
\hline VARIABLES & $\begin{array}{c}\text { (1) } \\
\text { IV } \\
M_{t} / P_{t}-M_{t-1} / P_{t-1}\end{array}$ & $\begin{array}{c}(2) \\
\mathrm{IV} \\
M_{t} / P_{t}-M_{t-1} / P_{t-1}\end{array}$ & $\begin{array}{c}(3) \\
\mathrm{IV} \\
\Delta M_{t}\end{array}$ & $\begin{array}{c}(4) \\
\mathrm{IV} \\
\Delta M_{t}\end{array}$ \\
\hline $\begin{array}{l}\left(M_{t-1}^{*}-M_{t-1}\right) / P_{t-1} \\
\left(\left(M_{t-1}^{*}-M_{t-1}\right) / P_{t-1}\right)^{2}\end{array}$ & $\begin{array}{c}0.084 \\
(0.011)^{* * *}\end{array}$ & $\begin{array}{c}0.089 \\
(0.013)^{* * *} \\
-0.004 \\
(0.002)^{* *}\end{array}$ & & \\
\hline $\begin{array}{l}M_{t-1}^{*}-M_{t-1} \\
\left(M_{t-1}^{*}-M_{t-1}\right)^{2}\end{array}$ & & & $\begin{array}{c}0.066 \\
(0.011)^{* * *}\end{array}$ & $\begin{array}{c}0.065 \\
(0.010)^{* * *} \\
-0.000 \\
(0.000)\end{array}$ \\
\hline $\begin{array}{l}\text { Observations } \\
\text { R-squared }\end{array}$ & 8,924 & $\begin{array}{l}8,924 \\
0.017\end{array}$ & $\begin{array}{l}8,946 \\
0.038\end{array}$ & $\begin{array}{l}8,946 \\
0.039\end{array}$ \\
\hline
\end{tabular}

$$
\begin{aligned}
& \text { Robust standard errors in parentheses } \\
& * * * \mathrm{p}<0.01,{ }^{*} \mathrm{p}<0.05,{ }^{*} \mathrm{p}<0.1
\end{aligned}
$$

Note: In the first two columns, each main independent variable was instrumented by its own numerator. This is because the denominator $\left(Y_{t-1}\right.$ as an estimate for $\left.P_{t-1}\right)$ in the main independent variable contains the same transitory component as the dependent variable does.

$\left(\Delta M_{i, t}=\alpha_{1}\left(M_{i, t-1}^{*}-M_{i, t-1}\right)\right)$ are similar (third and fourth columns). ${ }^{20}$ However, all these estimates remain subject to the omitted variable problem. ${ }^{21}$

The results in Tables 5 and 6 are consistent with the argument that the targets for precautionary savings affect actual savings over time. Assuming this, the earlier results in this paper imply that an experience of large expenditure may increase actual savings through a higher target for precautionary savings.

Is convergence faster for those who experienced an adverse event? The results are not conclusive. It may be natural to think that those who suffered large expenditure start taking wealth accumulation more seriously, and thus attempt to close the gap between the target for savings and actual savings more quickly than the rest of the population. To test this idea, I included the deviation interacted with the dummy of large expenditure experienced between one and two years ago in addition to the deviation term. (As before, $M_{i, t}$ is liquid assets as a proxy for precautionary savings.) Signs of the coefficients are consistent with the argument above, but the results are not very strong.

\footnotetext{
${ }^{20}$ Note that the level specification may be misspecified because equation (4) does not produce the level specification here.

${ }^{21}$ See the discussion above about the results of the last two columns of Table 5
} 
Table 7 Testing the Rate of Convergence

\begin{tabular}{|c|c|c|}
\hline VARIABLES & $\begin{array}{c}\text { (1) } \\
\text { IV } \\
M_{t} / P_{t}-M_{t-1} / P_{t-1}\end{array}$ & $\begin{array}{c}(2) \\
\mathrm{IV} \\
\Delta M_{t} \\
\end{array}$ \\
\hline$\left(\left(M_{t-1}^{*}-M_{t-1}\right) / P_{t-1}\right) \cdot D_{t-1}$ & $\begin{array}{c}0.033 \\
(0.038)\end{array}$ & \\
\hline$\left(M_{t-1}^{*}-M_{t-1}\right) / P_{t-1}$ & $\begin{array}{c}0.081 \\
(0.011)^{* * *}\end{array}$ & \\
\hline$\left(M_{t-1}^{*}-M_{t-1}\right) \cdot D_{t-1}$ & & $\begin{array}{c}0.042 \\
(0.027)\end{array}$ \\
\hline$M_{t-1}^{*}-M_{t-1}$ & & $\begin{array}{c}0.063 \\
(0.011)^{* * *}\end{array}$ \\
\hline Observations & 8,924 & 8,946 \\
\hline R-squared & 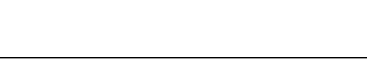 & 0.039 \\
\hline
\end{tabular}

Note: In the first column, the two main independent variables were instrumented by their own numerators. This is because the denominator $\left(Y_{t-1}\right.$ as an estimate for $\left.P_{t-1}\right)$ in the main independent variable contains the same transitory component as the dependent variable does.

In both of the ratio and level specifications, the coefficient is positive but insignificant (Table 7).

Retirement savings This paper has focused on precautionary savings, but in principle, a household's own experiences could have an impact on other types of savings. In particular, they may affect retirement savings. The implications of learning for retirement savings in the aggregate economy could be more important than those for precautionary savings, given the aggregate size of retirement savings.

In this context, using the JPSC, I tested another hypothesis - that households that have taken care of elderly parents over the past year may increase their targets for their retirement savings to (permanent) income ratios. ${ }^{22}$ The idea behind this hypothesis is that if households learn through parental care that the last stage in life is expensive, they may revise upward their targets for retirement savings.

The results fail to support the hypothesis (first column of Table 8), but the weak results may be simply because households reported in the JPSC are generally too young to respond to their experience of parental care. ${ }^{23}$ To examine this possibility, we could restrict the sample to households whose head is over a certain age, for example, age 45,

\footnotetext{
${ }^{22}$ The JPSC also reports targets for retirement savings.

${ }^{23}$ Theory implies that households start seriously accumulating wealth at a late stage in life Carroll (1997).
} 
Table 8 Regressions of Targets for Retirement Savings

\begin{tabular}{|c|c|c|}
\hline VARIABLES & $\begin{array}{c}(1) \\
\text { IV } \\
\Delta M_{t}^{*} / P_{t}\end{array}$ & $\begin{array}{c}(2) \\
\text { IV } \\
\Delta M_{t}^{*} / P_{t} \\
\text { head age } \\
>45\end{array}$ \\
\hline$D_{t}$ & $\begin{array}{c}0.157 \\
(0.215)\end{array}$ & $\begin{array}{c}0.075 \\
(0.384)\end{array}$ \\
\hline Observations & 6,294 & 1,233 \\
\hline R-squared & 0.017 & 0.038 \\
\hline
\end{tabular}

Note: $\Delta M_{t}^{*}$ refers to the target for retirement savings, while $D_{t}$ is 1 if a household has taken care of an elderly parent over the past year.

but that reduces the sample size to less than one-fifth of the full sample and does not help to produce stronger results (second column). ${ }^{24}$ Perhaps, to test the significance of learning on retirement savings in Japan, future research should examine micro data that contain more older households than covered by the JPSC. ${ }^{25}$

\section{Conclusions}

This paper tested the hypothesis that households in Japan learn from their adverse financial experiences and thus increase their targets for precautionary savings. The data suggest that households raise their targets for precautionary savings by $5-7$ percent of annual income in response to large expenditure events. Therefore, the aggregate impact of learning from (own) large events could be potentially substantial because about 10 percent of households experience such a shock each year (assuming that the targets for precautionary savings affect actual savings over time).

An area of future (and related) research is the impact of learning on retirement savings, which could be more important than precautionary savings from an aggregate perspective. This paper has failed to find evidence for learning associated with retirement savings, but that may be because of the undersampling of seniors in the JPSC.

\footnotetext{
${ }^{24}$ The results do not change much with an alternative age threshold.

${ }^{25}$ For the United States, the HRS is an ideal data set for such an analysis.
} 


\section{A Summary Statistics}

Table 9 reports averages of key variables by year. Note that $M^{*} / Y$ drops sharply in 2001 and stays lower subsequently. This may be reflecting the change in the question. Until 2000, the JPSC asked "For what purposes do you accumulate wealth? Please choose your first, second and third most important objectives, and report the target amount for each." Then, the survey listed 12 types of savings, including retirement savings, precautionary savings, and savings for children's education. In 2001, the JPSC changed the question slightly, and since then it has allowed respondents to report their target for savings for each purpose (not only three). It may be that before 2001, households overreported targets for precautionary savings (relative to 2001 and after) by including savings for other purposes in precautionary savings because they could report only three types of target.

Over time, household income $(Y)$ (deflated with $1993 \mathrm{CPI}$ ) rises, and heads (husbands) get older. The average of the key dummy $(D)$ is higher in the second half of the sample period, but the reason for this is not clear. The sample size increases over time, reflecting the fact that more women in the sample are married (recall that the JPSC tracks only women as respondents and that this paper restricted the sample to married households).

Table 9 Average of Key Variables

\begin{tabular}{cccccc}
\hline & $\begin{array}{c}\text { Target for } \\
\text { Precautionary } \\
\text { Savings to } \\
\text { Income Ratio } \\
\left(M^{*} / Y\right)\end{array}$ & $\begin{array}{c}\text { Actual } \\
\text { Income }\end{array}$ & $\begin{array}{c}\text { Dummy } \\
\text { Large } \\
\text { Expenditure }\end{array}$ & $\begin{array}{c}\text { Head } \\
\text { Age }\end{array}$ & $\begin{array}{c}\text { Number } \\
\text { of Obs }\end{array}$ \\
\hline Full sample & 0.29 & 658.6 & 0.10 & 38.9 & 7787 \\
1994 & 0.51 & 599.1 & 0.05 & 34.5 & 216 \\
1995 & 0.57 & 605.9 & 0.05 & 35.3 & 229 \\
1996 & 0.50 & 639.7 & 0.07 & 36.2 & 219 \\
1997 & 0.56 & 632.5 & 0.05 & 37.0 & 228 \\
1998 & 0.59 & 621.4 & 0.09 & 37.3 & 289 \\
1999 & 0.51 & 647.4 & 0.10 & 37.8 & 307 \\
2000 & 0.50 & 656.8 & 0.09 & 38.5 & 305 \\
2001 & 0.26 & 652.2 & 0.11 & 38.6 & 403 \\
2002 & 0.20 & 673.7 & 0.09 & 39.1 & 747 \\
2003 & 0.25 & 673.2 & 0.11 & 39.9 & 769 \\
2004 & 0.20 & 642.2 & 0.09 & 38.6 & 1046 \\
2005 & 0.23 & 660.6 & 0.12 & 39.3 & 1038 \\
2006 & 0.22 & 673.5 & 0.11 & 40.0 & 998 \\
2007 & 0.21 & 688.6 & 0.11 & 40.7 & 993 \\
\hline
\end{tabular}




\section{B Estimation of Convergence Using Theoretical Model}

By simulating the buffer stock model with multiple households, this appendix estimates the convergence process (equation (4)):

$$
M_{i, t} / P_{i, t}-M_{i, t-1} / P_{i, t-1}=\alpha_{1}\left(M_{i, t-1}^{*}-M_{i, t-1}\right) / P_{i, t-1}+\epsilon_{i, t} .
$$

Consider the buffer stock model where households (in the simulation) solve the following infinite horizon maximization problem: ${ }^{26}$

$$
\max \mathbb{E}_{t}\left[\sum_{n=0}^{\infty} \beta^{n} \mathrm{u}\left(C_{t+n}\right)\right],
$$

where $\mathrm{u}(\bullet)=\bullet^{1-\rho} /(1-\rho)$ is a constant relative risk aversion utility function. Households determine their consumption level $C_{t}$ given cash on hand $M_{t}$ and permanent noncapital income (level) $P_{t}$ (the two state variables). The budget constraint is:

$$
\begin{aligned}
C_{t} & \leq M_{t} \\
A_{t} & =M_{t}-C_{t} \\
M_{t+1} & =R A_{t}+P_{t+1} \theta_{t+1} \\
P_{t+1} & =G P_{t} \psi_{t+1},
\end{aligned}
$$

where $A_{t}$ is the assets at the end of period $t ; M_{t+1}$ is the sum of the interest $R$ times end-of-period assets and next-period noncapital income (equal to permanent noncapital income $P_{t+1}$ multiplied by a mean-one iid transitory income shock factor $\left.\theta_{t+1}\right)$; and $P_{t+1}$ is equal to its previous value, multiplied by a growth factor $G$ and a mean-one iid shock $\psi_{t+1}$. The simulation runs 9,000 households for 500 periods, and the convergence equation (above) is estimated using the last 2 periods of (simulated) cross-section data. ${ }^{27}$ The baseline parameter values for the simulation are gathered in Table 10.

Table 10 Baseline Parameter Values for Simulation

\begin{tabular}{lll}
\hline Parameter & Description & Value \\
\hline$\rho$ & Coefficient of relative risk aversion & 2 \\
$\beta$ & Discount factor & 0.98 \\
$G$ & Permanent income growth & 1.02 \\
$R$ & Interest rate & 1.02 \\
$\sigma_{\psi}$ & Log std. of permanent income shock & 0.1 \\
$\sigma_{\theta}$ & Log std. of transitory income shock & 0.1 \\
\hline
\end{tabular}

The estimates for the coefficient on $\left(M_{i, t-1}^{*}-M_{i, t-1}\right) / P_{i, t-1}$ cover a wide range, varying with parameter values. The first column of Table 11 indicates that with the baseline

\footnotetext{
${ }^{26}$ From Carroll (1997).

$27 M_{i, t-1}^{*} / P_{i, t-1}=m_{i, t-1}^{*}$ is calculated given a set of parameter values. In this exercise, $m_{i, t-1}^{*}$ is constant because parameters do not change over time or across households.
} 
parameter values (Table 10), the estimated coefficient is 0.21. Although changing impatience (lower or higher discount factor $\beta$ ) does not affect the sign of the coefficient, it changes the size of the coefficient significantly (second and third columns). Changing $G$ or $R$ gives similar results (not reported here). ${ }^{28}$ The results are also sensitive to the variance of income shocks (fourth and fifth columns).

The simulation supports nonlinearity in the convergence process. If the quadratic term $\left(\left(M_{i, t-1}^{*}-M_{i, t-1}\right) / P_{i, t-1}\right)^{2}$ is included in the equation, its coefficient is highly significant (Table 12). Moreover, the coefficient size of the quadratic term is in some cases quite large (close to 1), suggesting that the impact of nonlinearity could be quantitatively meaningful (unlike the implication of the empirical result in Table 6).

${ }^{28}$ Larger (smaller) $G$ or $R$ effectively implies higher (lower) impatience (Carroll (2004)). 
Table 11 Regressions of Convergence Process

\begin{tabular}{lccccc}
\hline & $(1)$ & $(2)$ & $(3)$ & $(4)$ & $(5)$ \\
& Baseline & $\beta$ & $\beta$ & $\sigma_{\psi}$ & $\sigma_{\psi}$ \\
VARIABLES & Params & 0.97 & 0.99 & 0.05 & 0.15 \\
\hline \multirow{2}{*}{$\left.M_{t-1}^{*}-M_{t-1}\right) / P_{t-1}$} & 0.21 & 0.28 & 0.06 & 0.37 & 0.03 \\
& $(0.01)^{* * *}$ & $(0.01)^{* * *}$ & $(0.00)^{* * *}$ & $(0.01)^{* * *}$ & $(0.00)^{* * *}$ \\
Observations & 9,000 & 9,000 & 9,000 & 9,000 & 9,000 \\
R-squared & 0.108 & 0.134 & 0.031 & 0.179 & 0.021 \\
\hline & Standard errors in parentheses & & \\
& $* * * \mathrm{p}<0.01, * * \mathrm{p}<0.05, * \mathrm{p}<0.1$ & &
\end{tabular}

Table 12 Regressions of Convergence Process with Quadratic Term

\begin{tabular}{lccccc}
\hline & $(1)$ & $(2)$ & $(3)$ & $(4)$ & $(5)$ \\
VARIABLES & Baseline & $\beta$ & $\beta$ & $\sigma_{\psi}$ & $\sigma_{\psi}$ \\
& Params & 0.97 & 0.99 & 0.05 & 0.15 \\
\hline$\left.M_{t-1}^{*}-M_{t-1}\right) / P_{t-1}$ & 0.30 & 0.40 & 0.08 & 0.50 & 0.02 \\
& $(0.01)^{* * *}$ & $(0.01)^{* * *}$ & $(0.00)^{* * *}$ & $(0.01)^{* * *}$ & $(0.00)^{* * *}$ \\
$\left(\left(M_{t-1}^{*}-M_{t-1}\right) / P_{t-1}\right)^{2}$ & 0.39 & 0.73 & 0.03 & 0.97 & -0.00 \\
& $(0.02)^{* * *}$ & $(0.04)^{* * *}$ & $(0.00)^{* * *}$ & $(0.04)^{* * *}$ & $(0.00)^{* * *}$ \\
Observations & & & & & \\
R-squared & 9,000 & 9,000 & 9,000 & 9,000 & 9,000 \\
\hline
\end{tabular}

Standard errors in parentheses

*** $\mathrm{p}<0.01,{ }^{* *} \mathrm{p}<0.05,{ }^{*} \mathrm{p}<0.1$ 


\section{References}

Allen, Todd M., And Christopher D. CArroll (2001): "Individual Learning About Consumption," Macroeconomic Dynamics, 5(4), Available at http://econ.jhu.edu/people/ccarroll/IndivLearningAboutC.pdf.

Ameriks, John, And Stephen P. Zeldes (2004): "How Do Household Portfolio Shares Vary With Age?," Mimeo.

Carroll, Christopher D. (1997): "Buffer Stock Saving and the Life Cycle/Permanent Income Hypothesis," Quarterly Journal of Economics, CXII(1), 1-56, Available at http://econ.jhu.edu/people/ccarroll/BSLCPIH.zip.

(2004): "Theoretical Foundations of Buffer Stock Saving," Revise and Resubmit, Review of Economic Studies, Latest version available at http: //econ.jhu.edu/people/ccarroll/BufferStockTheory.pdf.

Carroll, Christopher D., And Andrew A. Samwick (1998): "How Important Is Precautionary Saving?," The Review of Economics and Statistics, 80(3), 410-419.

Duflo, Esther, and Emmanuel Saez (2003): "The Role of Information and Social Interactions in Retirement Plan Decisions: Evidence from a Randomized Experiment," Quarterly Journal of Economics, 118(3), 815-842.

Dynan, Karen E., Jonathan Skinner, And Stephen P. Zeldes (2004): "Do the Rich Save More?," Journal of Political Economy, 112(2), 397-444.

Evans, George W., And Seppo Honkapohja (2009): "Expectations, Learning and Monetary Policy: An Overview of Recent Research," 13, 027-076.

Giuliano, Paola, and Antonio Spilimbergo (2009): "Growing Up in a Recession: Beliefs and the Macroeconomy," NBER Working Paper No. 15321.

Guiso, Luigi, Tullio Jappelli, And Daniele Terlizzese (1992): "Earnings Uncertainty and Precautionary Saving," Journal of Monetary Economics, 30(2), 30737 .

Kaustia, MarkKu, And SAmuli Knupfer (2008): "Do Investors Overweight Personal Experience? Evidence from IPO Subscriptions," Journal of Finance, 63(6), 2679-2702.

Lusardi, AnNAmaria (1997): "Precautionary Saving and Subjective Earnings Variance," Economics Letters, 57, 319-326.

(1998): "On the Importance of the Precautionary Saving Motive," American Economic Review Papers and Proceedings, 88(2), 449-453.

Paper.

(2003): "Planning and Savings for Retirement," Dartmouth College Working 
(2005): "Saving and the Effectiveness of Financial Education," Journal of Financial Transformation, 15, 159-169.

Lusardi, Annamaria, And Olivia S. Mitchell (2007): "Baby Boomer Retirement Security: The Roles of Planning, Financial Literacy, and Housing Wealth," Journal of Monetary Economics, 54(1), 205-224.

Malmendier, UlRike, AND Stefan NAgel (2011): "Depression Babies: Do Macroeconomic Experiences Affect Risk Taking?," Quarterly Journal of Economics, 126(1), 373-416.

Owen, Ann L., And Stephen Wu (2007): "Financial Shocks and Worry about the Future," Empirical Economics, 33(3), 515-530. 